\title{
Ocular leprosy in Uganda
}

\author{
V.P. EMIRU \\ Eye Department, Mulago Hospital, Kampala, Uganda
}

Leprosy has been noted to cause more ocular complications than any other systemic bacterial disease (Mendonça de Barros, 1946). Before the advent of sulphone treatment almost every leprosy patient sooner or later developed an ocular complication (Prendergast, I940; Mendonça de Barros, 1946), but modern treatment has reduced the incidence of ocular complications judging from the more recent reports (Holmes, I957; Chatterjee and Ghaudhury, 1964; McLaren, Shaw, and Dalley, 196ı; Grawford, I969; Ticho and Ben Sira, 1970). Nevertheless, leprosy still causes much morbidity in all countries where it is endemic.

The incidence of the ocular complications of leprosy varies from one country to another, because of differences in the availability of and the amenability of the people to modern treatment, the stage of the disease at which treatment is commenced, and the relative frequency of the main clinical types of the disease. Where there is more lepromatous than tuberculoid leprosy, the incidence of ocular complications tends to be higher (Chattere jee and Chaudhury, 1964). The range of the age of the people screened may also lead to variation, as the proportion of ocular involvement increases with age. Furthermore there also seem to be regional variations, since it has been noted that lepromatous ocular lesions are more common in temperate than in tropical areas (Doull, 1959).

The ocular complications of leprosy in Uganda have not been reported before. Although the incidence of the various ocular lesions broadly follows the general pattern, the data from this survey lends support to findings from other parts of Africa, that certain eye lesions are uncommon in this region.

\section{Material and Method}

The inmates of the main leprosaria in Uganda (Nyenga, Buluba, Kumi, and Alito) were screened for ocular complications of leprosy. Examination was done by direct inspection in daylight. The visual acuity was assessed in all cases and a patient whose vision had been reduced to counting fingers or less was recorded as blind. The cornea and iris were inspected using a $\times$ ro monocular loupe with focal illumination. The fundus was examined in some cases, but since this could not be done in all of them, the data given here is confined to the anterior segment of the eye and the adnexa.

\section{Findings (Table I, opposite)}

The incidence of the ocular complications among 890 patients examined was $2 \mathrm{I} \cdot 2$ per cent. There was no significant difference in incidence between the sexes, but ocular lesions were not seen in children and there was only one case of lagophthalmos among young adults below the age of 20 years. There were no complications in patients who had had the disease for 2 years. All the children and young adults had either had the disease for a short time or had had treatment from the early stage of the disease. 
Table I Ocular lesions in leprosy

\begin{tabular}{|c|c|c|c|c|c|}
\hline \multirow{2}{*}{ Eye lesion } & \multicolumn{2}{|l|}{ Sex } & \multicolumn{3}{|c|}{ Type of leprosy } \\
\hline & Male & Female & Lepromatous & Tuberculoid & Borderline \\
\hline Madarosis & 45 & 28 & 50 & 15 & 8 \\
\hline Lagophthalmos & 27 & 23 & 9 & $3^{8}$ & 3 \\
\hline Entropion & 5 & 4 & 6 & 3 & - \\
\hline Lacrimal obstruction & - & $\mathbf{I}$ & - & $\mathbf{I}$ & - \\
\hline Blepharitis & 2 & - & $\mathbf{I}$ & I & - \\
\hline Subepithelial punctate keratitis & 6 & 6 & 3 & 7 & 2 \\
\hline Pannus & 3 & 2 & 3 & I & $\mathbf{I}$ \\
\hline Corneal nodule & I & - & $\mathbf{I}$ & 一 & - \\
\hline Episcleral nodule & 3 & I & 4 & - & - \\
\hline Episcleritis & 2 & - & 2 & - & - \\
\hline Chronic iridocyclitis & 19 & 9 & 19 & 6 & 3 \\
\hline Iris pearl & $\mathbf{I}$ & - & $\mathbf{I}$ & - & - \\
\hline
\end{tabular}

Madarosis was the most frequent lesion, and among 73 patients with this lesion, fifty had lepromatous leprosy. The next most common lesion was lagophthalmos, mainly in cases of tuberculoid leprosy. Although chronic iridocyclitis was found in only 28 patients, it was the most serious complication. Entropion from leprosy was found among nine patients. Only one patient had miliary lepromata of the iris.

Twelve patients were blind in one or both eyes, four being totally blind. Chronic iridocyclitis accounted for blindness in eight patients and the other four patients became blind from exposure keratitis due to lagophthalmos. Lepromatous leprosy caused most of the blindness as depicted in the Figure.

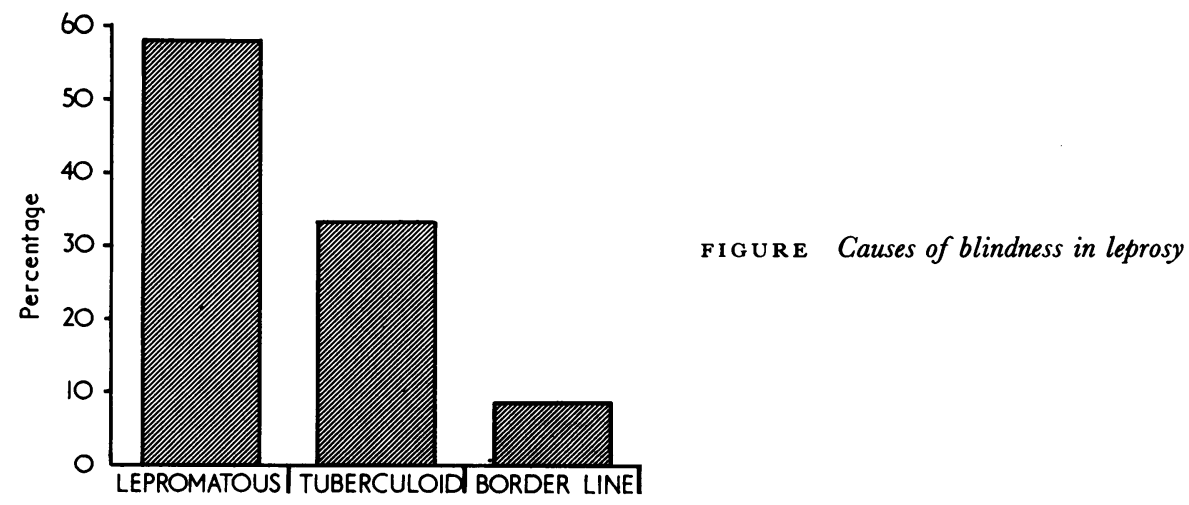

The incidence of the ocular lesions increased with age, being rare in young adults, and most frequent in the middle age group (Table II, overleaf).

\section{Discussion}

Certain ocular complications of leprosy seem to be rare in some parts of Africa. Miliary lepromata or iris pearls and subepithelial punctate keratitis are said to be extremely common and characteristic of leprosy (Choyce, 1959, I969), but in some parts of Africa 
Table II Distribution of ocular lesions according to age group

Ocular lesion

Madarosis

Lagophthalmos

Entropion

Subepithelial punctate keratitis

Pannus

Episcleral nodule

Episcleritis

Chronic iridocyclitis

Iris pearl

\begin{tabular}{|c|c|c|c|c|c|c|c|}
\hline I-IO & $10-20$ & $20-30$ & $30-40$ & $40-50$ & $50-60$ & $60-70$ & $70+$ \\
\hline - & - & 3 & 20 & 30 & 12 & 7 & I \\
\hline- & I & 3 & I 5 & 17 & 8 & 6 & - \\
\hline- & - & - & I & 4 & I & 3 & - \\
\hline-- & - & I & 2 & 6 & 2 & $\mathbf{I}$ & - \\
\hline- & - & - & - & 4 & I & - & - \\
\hline- & - & I & I & I & I & - & - \\
\hline- & - & - & 1 & I & - & - & - \\
\hline- & - & I & 5 & 9 & 4 & 5 & 4 \\
\hline- & - & - & - & - & I & - & - \\
\hline
\end{tabular}

these lesions seem to be rare. Thus in Brazil, 69 patients among 1,279 had iris pearl (Mendonça de Barros, I946), and in Panama 26 per cent. of leprosy patients had iris pearl (Harley, I946), but in Tanganyika, McLaren and others (I96I) found only one case of miliary lepromata of the iris among I,200 patients examined; in Ghana, no iris pearl was seen among $25^{\circ}$ patients (Ghatterjee and Chaudhury, 1964); and in Malawi, only a few cases of miliary lepromata were seen in 8,325 patients (Ticho and Ben Sira, I 970). In the present survey in Uganda, only one of the 890 patients had an iris pearl. Subepithelial punctate keratitis is equally uncommon in Tanganyika, Ghana, Malawi, an $\$$ Uganda, as compared to some other countries (Harley, 1946). The reason for this peculiar variation is not known.

Lagophthalmos is a fairly common lesion in leprosy. But relatively few patients develop exposure keratitis. Bell's phenomenon seems to protect the cornea for a long time. The process of facial nerve palsy is a slow one. It has been noted that many years pass before lagophthalmos can produce exposure severe enough to cause keratitis (Chatterjee and Chaudhury, I964). Hence, although lagophthalmos is more common than chronic iridocyclitis, it causes less blindness than the latter.

Entropion is a complication of leprosy about which little has been written in the past. McLaren and others ( 1961 ) seem to have been the first to record the occurrence of entropion in leprosy. Richards and Arrington (1969) mention entropion as a sign of leprosy. Among the 890 patients in the present survey there were nine with entropion which was considered to be due to no other cause but leprosy. Although trachoma is endemic in Uganda, entropion from leprosy is distinctive in that there is no scarring of the conjunctiva. Entropion in leprosy is probably due to invasion of the lid by the bacillus, but biopsy of the tarsal plate in one of the nine cases showed only non-specific inflammatory changes and not the characteristic inflammatory reaction of leprosy. Entropion should be corrected in the usual way by tarsotomy (Hadija, I960).

Apart from lagophthalmos in one patient, none of the I 54 children and young adults below the age of 20 years had ocular lesions. This is because of the short duration of the disease in some and also because those who had had the disease for many years had been treated from the early stages. Modern treatment seems to reduce the incidence of ocular complications and the incidence of blindness in leprosy seems to be on the decline. Thus before the advent of sulphone treatment, Prendergast (1940) and Harley (1946) reported an incidence of 29 and 13 per cent. of blindness respectively. But after about one decade 
of sulphone treatment the incidence of blindness was found to be 6 per cent. (Doull, I959) in the Rukyus Islands. More recently, in Ghana (Chatterjee and Chaudhury, 1964) and Malawi (Ticho and Ben Sira, 1970), the incidence of blindness in one or both eyes was only $\mathrm{I} \cdot 4$ and $0 \cdot 3$ per cent. respectively. In Uganda there was a similarly low incidence of blindness in one or both eyes of $\mathrm{I} \cdot 3$ per cent. In Northern Nigeria (Grawford, I969) the prevalence of leprosy has been reduced after mass treatment with Dapsone. Data from Malawi indicates a significant reduction of ocular complications among patients treated with Dapsone as compared with an untreated group (Ticho and Ben Sira, 1970). In Uganda it has been noted that with the present variety of specific drugs, and with steroids to stop acute reactions, every fresh case of leprosy of whatever type has a fair chance of recovery without mutilation (Blenska, 1969). If it is established that modern treatment reduces the prevalence of the disease and the incidence of complications, then the prediction (Choyce, I969) that "the number of blind leprosy patients will increase in the next 20 to 30 years" will not be substantiated.

\section{Summary}

The incidence of the ocular complications of leprosy in Uganda is reported. Iris pearls and subepithelial punctate keratitis were found to be uncommon and this agrees with similar findings in Tanganyika, Ghana, and Malawi, but the reason for this regional variation is not known.

Complications were rare in young people who had been treated from the early stage of the disease. Moreover, the incidence of blindness, which was reported to be high in other countries before sulphone treatment, was found to be only $\mathrm{I} \cdot 3$ per cent.

\section{References}

Blenska, w. (I969) The Uganda Practitioner, 2, 9

ChatterJee, s., and chaudhury, D. s. (ig64) Int. J. Leprosy, 32, 53

CHOYCE, D. P. (1959) In "Leprosy in Theory and Practice", ed. R. G. Cochrane, pp. I6o. Wright, Bristol

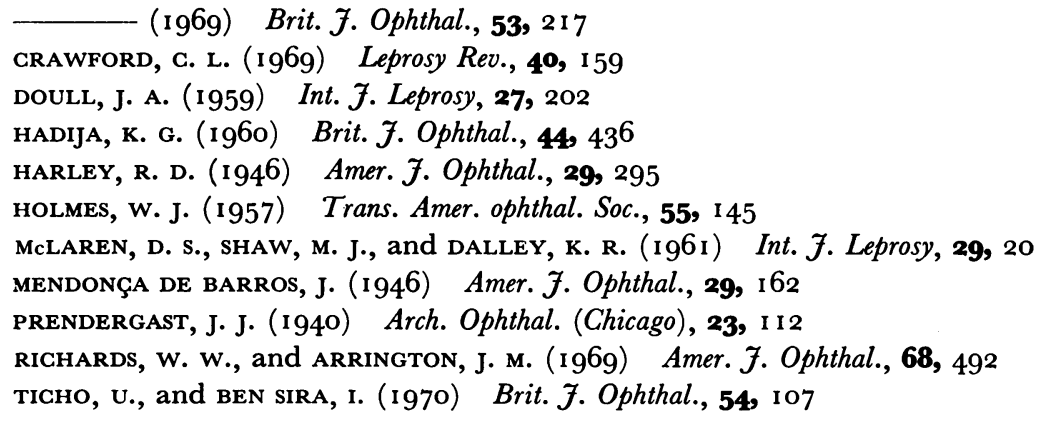

